\title{
PROCESSOS E POTENCIALIDADES DE COMUNICAÇÃO: INTERAÇÃO NAS INTERFACES GESTUAIS DOS TABLETS
}

VIVIAN RODRIGUES DE OLIVEIRA

Universidade Federal de Santa Catarina Florianópolis, Santa Catarina, Brasil. e-mail:vivianunb@gmail.com

RITA DE CÁSSIA ROMEIRO PAULINO Universidade Federal de Santa Catarina Florianópolis, Santa Catarina, Brasil. e-mail:rcpauli@gmail.com 
PROCESSOS E POTENCIALIDADES DE COMUNICAÇÃO: INTERAÇÃO NAS INTERFACES GESTUAIS DOS TABLETS

Resumo: O surgimento e a difusão dos dispositivos tablets evidenciaram a interface espacial e sensível ao toque. $O$ design de interação, a linguagem de comunicação híbrida e a interface gestual trouxeram questões importantes acerca dos padrões de usabilidade nos tablets. Neste estudo, centrado nas potencialidades de interação do usuário com as interfaces gestuais nos tablets, busca-se relacionar a dinâmica dos processos de linguagem e cognição às características identificadas nestes dispositivos.

Palavras chave: tablet; interface; linguagem gestual; cognição; touchscreen.

LOS PROCESOS Y CAPACIDADES DE COMUNICACIÓN: LA INTERACCIÓN EN LAS INTERFACES GESTUALES PARA TABLETAS

Resumen: La aparición y difusión de dispositivos de tablets mostró la interfaz espacial y pantalla táctil. Por lo tanto, el diseño de interacción, el lenguaje híbrido e interfaz gestual traído importantes preguntas y respuestas sobre las normas de uso en tablets. Este estudio se centró en las posibilidades de interacción de los usuarios con interfaces gestuales en tablets, tratando de relacionar la dinámica de los procesos de las características del lenguaje y la cognición identificados en estos dispositivos y sus aplicaciones.

Palabras clave: tablet; interfaz; lenguaje por señas; cognición; touchscreen.

PROCESSES AND CAPABILITIES OF COMMUNICATION: INTERACTION IN GESTURAL INTERFACES FOR TABLETS

Abstract: The advent and spread of tablet devices showed the spatial interface and touchscreen. Thus, the interaction design, the hybrid language and gestural interface brought important questions and answers about the standards of usability in tablets. This study, focused on the potential for user interaction with gestural interfaces in tablets, seeks to relate the dynamics of the processes of language and cognition characteristics identified in these devices and their applications.

Keywords: tablet; interface; gestural language; cognition; touchscreen. 


\section{INTRODUÇÃO}

O tablet é um aparelho digital portátil, pessoal e em forma de prancheta; além disso, dotado das capacidades básicas de um computador e habilitado a desencadear ações que respondam ao toque em sua tela. Portabilidade, acesso à internet, suporte multimídia e touchscreen (tela sensível ao toque) são alguns dos atributos que tornam este dispositivo um genuíno representante da tecnologia móvel do século XXI - bem como um dos modelos de negócio mais requisitados por multinacionais de tecnologias de comunicação.

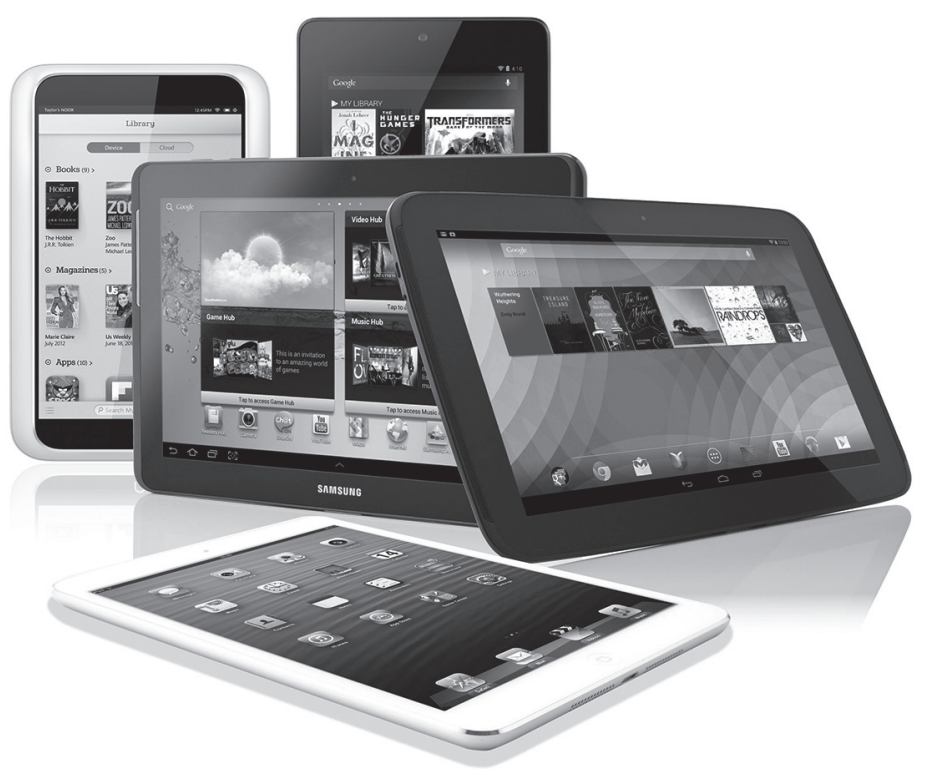

Figura 1 - Tablets do mercado

Fonte: http:// http://www.pcadvisor.co.uk/features/tablets/3416876/best-tablets-of-2012/

O mercado dos tablets triplicou no Brasil em 2012: o país passou de $17^{\circ}$ para $10^{\circ}$ lugar no ranking mundial do consumo, segundo pesquisa do International Data Corporation (IDC). Apenas no $3^{\circ}$ trimestre de 2012 foram vendidos 769 mil tablets no país. Ainda assim, o mercado brasileiro de tablets é 12 vezes menor que o mercado norte-americano, o maior consumidor do mundo. Atualmente, os principais tablets do mercado brasileiro e mundial são: Novo iPad (Apple); Galax Tab 10.1 (Samsung); e Motorola XOOM 2 (Motorola).

Com a notoriedade dos dispositivos móveis, a produção de jornais digitais no formato de aplicativos também se popularizou, despertando novos desafios para a linguagem jornalística. Atributos envolvendo o layout, as interfaces, 
as tipografias, os padrões de zoom e as disposições da navegação valorizam o conteúdo e são determinantes para a sua adequação nestes aparelhos. As principais características dos aplicativos levam em conta sua possibilidade de orientação dupla e função touchscreen. Além disso, a leitura multimídia, a interatividade e o hipertexto são elementos fundamentais da linguagem híbrida que compõe as publicações para tablets (PAULINO, 2012):

A publicação digital em tablets conduz o leitor a uma viagem midiática pelo conteúdo. Essa nova narrativa deve instigá-lo a explorar as páginas, buscar botões, procurar opções de áudio, vídeo e animações para complementar o conteúdo, tornando a atividade de leitura mais lúdica e interessante (PAULINO, 2012, p.5).

Segundo estudo da Alliance for Audited Media, em 2012, 90\% das publicações jornalísticas americanas possuíam aplicativos pra tablets. No Brasil, esse número também cresce, de modo que os jornais de maior circulação (O Globo, Folha de S. Paulo e O Estado de S. Paulo) já incorporaram essa forma de distribuição de suas publicações em complemento às suas versões impressas e digitais. O jornal O Globo disponibiliza um produto com conteúdo exclusivo para tablets, o jornal vespertino O Globo A Mais. Entre as revistas que já possuem seus aplicativos para tablets, estão: Revista Época, Revista Istoé, Revista Autoesporte, Revista Galileu, Revista Carta Capital e Revista Veja.

\subsection{A interface sensível ao toque}

A tactibilidade participa ativamente da construção de notícias e outras narrativas em interfaces de tablets, as quais possibilitam o estímulo cutâneo e cinestésico; e também são conhecidas como interfaces hápticas. Estas associam o gesto do toque à cinestesia (HAYWARD, Vincent et all, 2004). "O sistema háptico está relacionado com a percepção de textura, movimento e forças através da coordenação de esforços dos receptores do tato e visão" (SARAIVA, A. J, et al, 2010, p. 10).

A tela sensível ao toque convida o usuário a um potencial de interatividade de navegação pouco identificado em mídias anteriores. A possibilidade de entrada de informação por meio do movimento das mãos em contato com a tela lançou um novo olhar a respeito da linguagem gestual e suas possibilidades e 
limitações na interação homem-computador. Até mesmo sistemas de informação que não levavam em conta a capacidade do toque e do gesto passaram a agregar estes elementos em sua usabilidade, como o Windows 8 ( ver Figura 2).

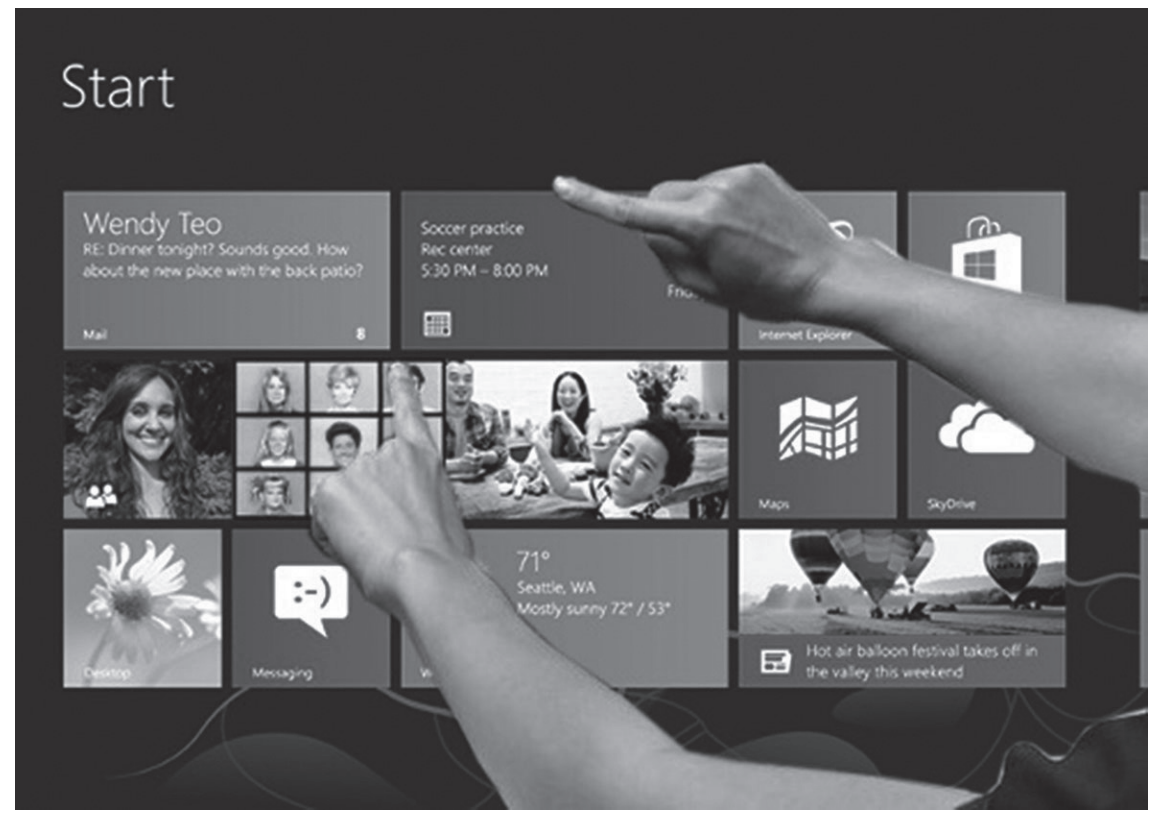

Figura 2 - Interface do sistema operacional Windows 8

Fonte: http://truxtertech.com/2012/10/are-you-ready-to-jump-to-windows-8-yet/

A interface do Windows 8 foi completamente otimizada para a funcionalidade touchscreen. Esta universalização do sistema operacional em relação ao hardware - além da adaptação ao toque - foi considerada pela comunidade tecnológica o grande salto da Microsoft em relação à versão anterior do sistema. Além disso, o Windows 8 foi lançado em cojunto com a primeira linha de tablets da empresa, o Microsoft Surface.

No mercado dos jogos eletrônicos, a popularização de aparelhos cujos sensores de movimentos de última geração permitem a interatividade sem a necessidade de acessórios extrernos já está tornando as interfaces cada vez mais naturais (NUI - Natural User Interface). As metáforas das interfaces elencadas por Scolari (2004) - conversacional, instrumental, superficial e espacial - são uma emblemática referência para entender a constante negociação entre o designer e o usuário no processo de interatividade, bem como o papel que cada um deles assume neste processo: 
Dentro da interface se instala um intercâmbio simbólico, uma conversação virtual entre o designer implícito (enunciador) e o usuário implícito (enunciatário). Esse diálogo funciona como proposta de interação dirigida ao usuário empírico, que poderá aceitar ou não. Mas os sujeitos virtuais presentes nos processos de interação não se esgotam nestas entidades fantasmagóricas - os simulacros do designer e do usuário - que convivem dentro de uma interface. (SCOLARI, 2004, p.159)

O aperfeiçoamento de interfaces a fim de que estas se tornem mais amigáveis e intuitivas sempre foi um dos alvos dos estudos do design e da ciência da computação. Desde as antigas interfaces baseadas em linhas de comando acionadas por um teclado (MS-DOS) - passando pela metáfora do escritório concebido pela Microsoft Windows - até chegar à linguagem gestual dos tablets e jogos eletrônicos, a busca pelo melhor desenho da informação digital é um desafio em meio às velozes transformações de hardware e software.

Este estudo está centrado na interação entre o usuário e as interfaces dos tablets, considerando as dinâmicas inerentes aos processos de linguagem e cognição durante o consumo da informação. Adotou-se uma abordagem exploratória, a partir de um levantamento sistemático da literatura e das abordagens correntes no âmbito das práticas de letramento digital e dos processos de produção e consumo de produtos jornalísticos em tablets. Finalmente, do ponto de vista dos procedimentos técnicos, esta pesquisa pode ser classificada como bibliográfica e empírica (SILVA; MENEZES, 2001, p.21).

\section{DA ORALIDADE AO SUPORTE DIGITAL}

A escrita cuneiforma desenvolvida pelos Sumérios por volta de 3.500 a.C era gravada em tabuletas de argila parecidas com as pranchetas eletrônicas hoje conhecidas como tablets, conforme figura 3. Ainda que as similaridades dos suportes não avançem além disto, elas ajudam a pensar o processo de leitura e escrita numa perspectiva evolutiva, como um reflexo das transformações de linguagem e cognição do homem. 


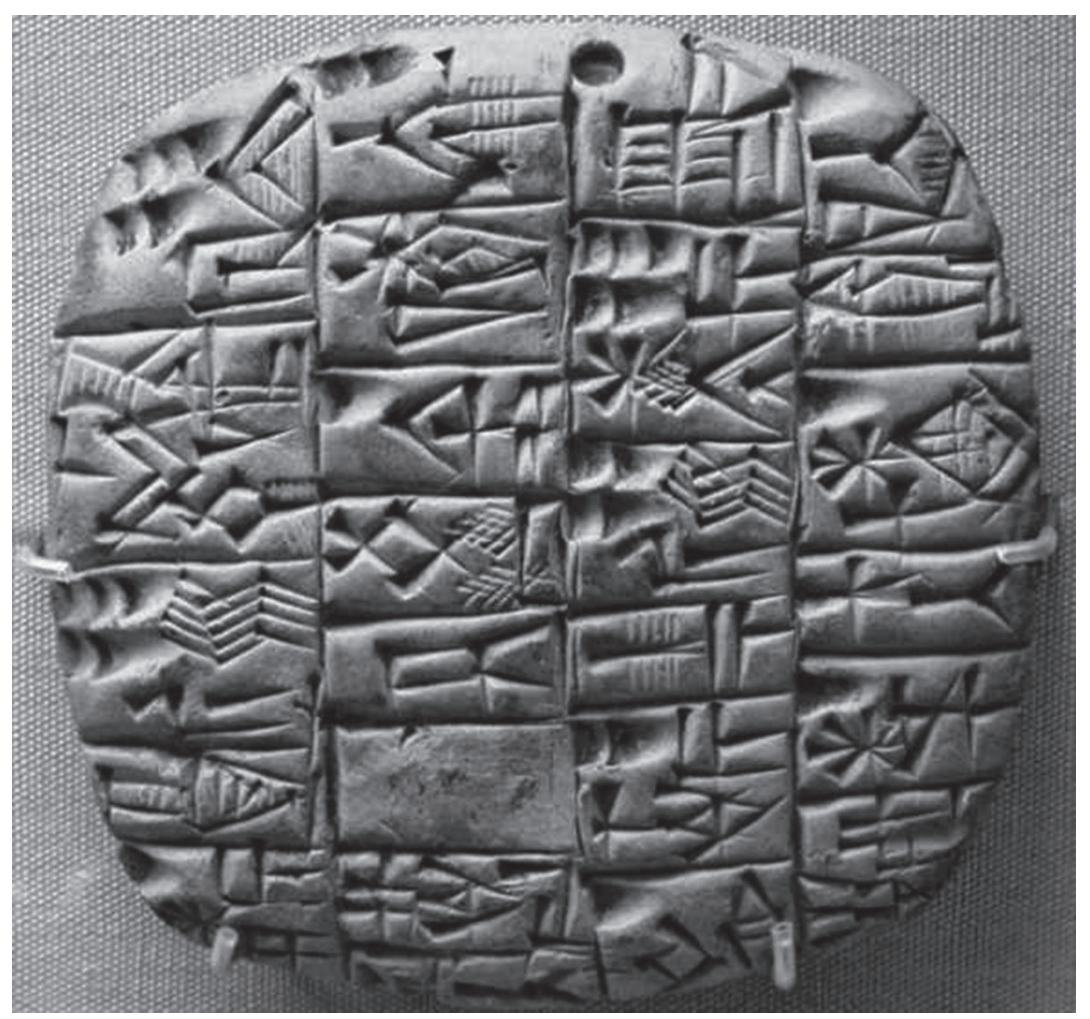

Figura 3 - Tabuleta de argila com inscrição da escrita suméria Fonte: http://www.portalsaofrancisco.com.br/alfa/civilizacao-sumeria/imagens/Escrit32.jpg

Da oralidade à escrita, da escrita ao impresso e do impresso ao digital, a humanidade passou por importantes transformações tecnológicas, culturais e biológicas. As pesquisas trataram de buscar diferentes áreas do conhecimento para explicar a relação do homem com a escrita/leitura em meio à profusão de suportes e formas de comunicação.

O desenvolvimento de representações gráficas se relaciona com múltiplos eventos e dinâmicas sociais. É sabido, por exemplo, que o aparecimento da imprensa guarda uma relação íntima com o desenvolvimento da escrita a partir dos tipos móveis de Gutenberg. Ao explicar sua famosa teoria a respeito de "meios quentes" e "meios frios", o canadense McLuhan utilizou a escrita (seus suportes e meios de distribuição) para exemplificar suas convicções: “Um meio frio como os caracteres escritos hieroglíficos ou ideogrâmicos atua de modo muito diferente daquele de um meio quente e explosivo como o do alfabeto fonético" (MCLUHAN, 1977, p.39).

Para além das comparações entre os aspectos produzidos pelos meios, 
Chartier (2002) discorreu sobre as intervenções físicas e cognitivas do próprio corpo humano no modo de leitura durante o monopólio da escrita:

[...] a leitura do rolo com a Antiguidade era uma leitura contínua, que mobilizava o corpo inteiro, que não permitia ao leitor escrever enquanto lia. Sabemos que o Códex, manuscrito ou impresso, permitiu gestos inéditos (folhear o livro, citar trechos com precisão, estabelecer índices) e favoreceu uma leitura fragmentada, mas que sempre percebia a totalidade da obra, identificada por sua própria materialidade. (CHARTIER, 2002, p.30)

O surgimento da escrita, em 3.500 a.C, é atribuído à civilização Suméria que habitava a antiga Mesopotâmia, na Ásia. Os sumérios usavam como suporte as já citadas tábuas de argila que eram molhadas e marcadas por um estilete feito de cana e em forma de cunha, por isso, o nome "escrita cuneiforme". Juntamente com o desenvolvimento da escrita cuneiforme, os historiadores acreditam que os egípcios também tenham desenvolvido a escrita mais antiga de que se tem conhecimento: os hieróglifos egípcios (Figura 4). Eram inscrições em papiro e nas paredes de templos e túmulos que poderiam utilizar quase sete mil tipos de sinais.
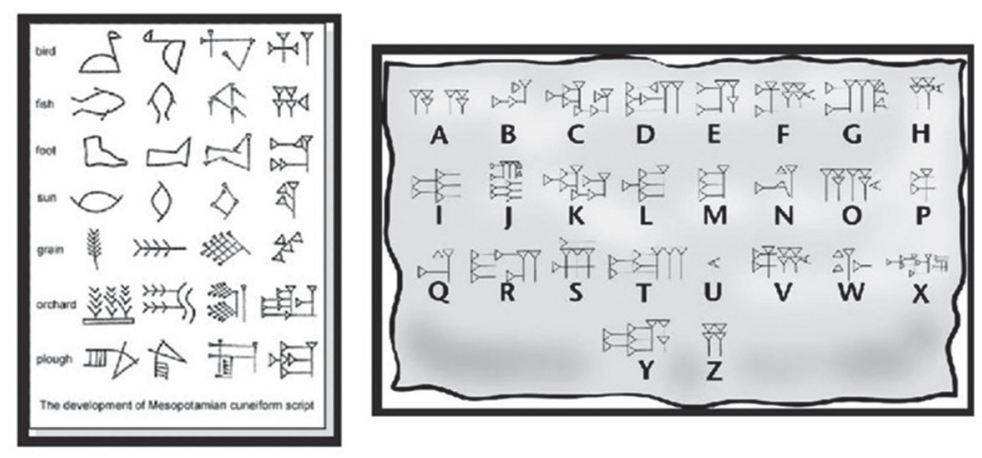

Figura 4 - Escrita cuneiforma suméria e os hieróglifos egípcios (da esquerda para a direita) Fonte: http://orienteantigo.blogspot.com.br/2007/08/tradutor-de-escrita-cuneiforme-e.html

Segundo Maryanne Wolf (2007), existem três etapas importantes para se compreender a história e ciência por trás de um cérebro leitor: a história antiga 
de como as espécies aprenderam a ler desde os Sumérios até Sócrates; o desenvolvimento do ciclo de vida dos humanos tal como eles aprenderam a ler de todas as formas mais sofisticadas ao longo dos anos; e a história e a ciência do que acontece quando o cérebro é capaz de aprender a ler. A neurocientista defende que a leitura é uma invenção humana que reflete a forma como o cérebro se reorganiza para aprender algo novo. Cada novo cérebro leitor possui a capacidade de reorganizar-se para além das suas capacidades originais, a fim de compreender os símbolos escritos.

O homem ensinou o cérebro a ler apenas alguns milhares de anos atrás, e esse processo mudou a evolução intelectual da espécie. $O$ cérebro que examinou minúsculos tabletes de argila na escrita cuneiforme dos sumérios é configurado de modo diferente do cérebro que lê alfabetos ou textos multimídia na tela do computador. Wolf (2007) defende que o cérebro tem a capacidade "protéica de fazer novas conexões entre as estruturas e circuitos originalmente destinados a outros processos cerebrais mais básicos (...) como a visão e a língua falada" (WOLF, M., p.5, 2007, tradução nossa).

A tese da autora acerca do funcionamento do cérebro no aprendizado da leitura é de que o órgão é uma espécie de "arquitetura aberta", logo, altamente capaz de se adaptar a novas linguagens:

[...] grupos de neurônios criam novas conexões e caminhos entre si cada vez que adquirem uma nova habilidade. Cientistas da computação usam o termo "arquitetura aberta" para descrever um sistema que é versátil o suficiente para mudar - ou reorganizar - para acomodar as diferentes demandas sobre ele. Dentro das limitações de nossa herança genética, o nosso cérebro apresenta um belo exemplo de arquitetura aberta. A leitura pode ser aprendida apenas por causa do design plástico do cérebro, e quando a leitura tem lugar, o cérebro do indivíduo é mudado para sempre, tanto fisiologicamente e intelectualmente. (WOLF, M., 2007, p.5, tradução nossa)

Os aspectos cognitivos são parte indissociável da evolução dos processos de escrita e leitura. Não basta, entretanto, observá-los apenas em seu sentido biológico ou anatômico. Para Santaella (2004) a interação está na medula dos processos cognitivos. Ao conceituar o fenômeno da interatividade, a pesquisadora recorre a Kretz (1985 apud Santaella, 2004) para categorizar os diferentes níveis de interação: 
* Interatividade zero - os meios são consumidos linearmente do começo ao fím

* Interatividade linear - quebra-se a sequência (avanços e recuos) de leitura durante o contato com o meio

* Interatividade arborescente - existe uma seleção em menu, uma escolha em relação à parte a qual ser quer explorar

* Interatividade linguística - busca-se palavras-chave e formulários para filtrar o que interessa na leitura do meio

* Interatividade de criação - conteúdos e mensagens são compostos por correspondência

* Interatividade de comando contínuo - permite a modificação, o deslocamento de objetos sonoros ou visuais mediante a manipulação do usuário, como nos videogames

De acordo com esta categorização, a escrita em suporte impresso ou manuscrita permite apenas a análise da interatividade "zero" ou "linear". É na passagem do impresso para o digital que serão observadas as revoluções mais significavas da linguagem sob as perspectivas da interação e da cognição. A linguagem digital parece responder a aspiração de concepção de uma linguagem universal, que supre a necessidade de uma língua comum representada por signos, símbolos, tabelas, quadros (CHARTIER, 2002). A capacidade de colocar todas as linguagens dentro de uma raiz comum permite à linguagem digital que todas as linguagens se misturem durante sua formação (SANTAELLA, 2004).

Com o aparecimento do digital, Chartier (2002) discorre sobre uma "tríplice ruptura": nova técnica de difusão da escrita; nova relação com os textos; e nova forma de inscrição. Existem, então, três revoluções: a revolução da modalidade da técnica da produção da escrita; a revolução da percepção das entidades textuais; e a revolução das estruturas e formas mais fundamentais dos suportes da cultura escrita.

As linguagens, contudo, jamais perderam a capacidade de coexistência e contaminação diante da invasão das possibilidades oferecidas pelas tecnologias da informação e da comunicação (TIC's). Atravessar a ponte do impresso ao digital significa ir ao encontro de uma nova (e híbrida) ferramenta de elaboração de uma mensagem: a hipermídia. Se texto, som e imagem podem se misturar em um mesmo espaço, a escrita experimenta uma reestruturação em sua essência: 
Tenho chamado atenção para o fato de que, diferentemente da revolução gutenberguiana, a hipermídia não incide apenas no modo como se produz e reproduz a escrita. Embora também envolva esse aspecto, a hipermídia vai muito além. Trata-se de uma nova maneira de se produzir o texto escrito na sua fusão com as outras linguagens, algo que transforma a escrita no seu âmago, colocando em questão a natureza mesma da escritura e dos seus potenciais. (SANTAELLA, 2007, p.85)

Alguns autores acreditam que a linguagem digital é, sobretudo, uma linguagem híbrida, ou até mesmo "cíbrida", de acordo com Santaella (2007). A autora defende que o cruzamento e a integração de elementos de comunicação no mundo digital proporcionaram mudanças no modo como eles são percebidos não apenas juntos, como também isoladamente:

O computador não nos coloca apenas diante de um novo tipo de tecnicidade, mas traz consigo uma linguagem cíbrida, ou seja, o hibridismo sígnico e midiático que é próprio do ciberespaço. É notório que os conceitos de escritura e de texto vêm passando por transformações profundas desde que as tecnologias digitais emergiram. A integração do texto, das imagens dos mais diversos tipos, fixas e em movimento, e do som, música e ruído, em uma nova linguagem híbrida, mestiça, complexa, que é chamada de hipermídia, trouxe mudança para o modo como não só o texto, mas também a imagem e o som costumavam ser entendidos. (SANTAELLA, 2007, p.84)

\subsection{As interfaces como metáforas}

Para estudar os modelos de interfaces implantados ao longo dos anos, Scolari (2004) tratou de destrinchar as comparações projetadas na construção destes dispositivos e destacou as quatro mencionadas metáforas das interfaces: (1) conversacional - intercâmbio entre instruções e respostas programadas; (2) instrumental - sistemas operativos caracterizados por um entorno gráfico de interação denominado WIMP (Windows, Icons, Mouse, Pointer); (3) superficial - superfície osmótica que separa/permite o intercâmbio homem-computador; e (4) espacial lugar, prótese e comunicação, ou seja, a interface como lugar da interação.

O autor considera que a metáfora espacial é a que melhor explica o lugar da interface na relação com o usuário. Para ele, a interface espacial é a mais 
completa e desenvolvida porque considera o processo interativo no seu todo. A interface é um espaço onde se articula a interação entre o corpo humano, a máquina e a finalidade da interação; onde o trabalho do designer se dá em termos arquitetônicos.

Scolari (2004) diz ainda que a teoria crítica semiotiza a interação, ou seja, reconhece a distância existente entre a estratégia do designer e a estratégia do usuário, além de pensar a interação em termos polêmicos contratuais. Santaella (2004) concorda com a conclusão e acredita ainda que a hibridização de linguagens; a organização não linear dos fluxos informacionais; a cartografia de navegação; e o agenciamento interativo do usuário é o que caracteriza de modo mais completo a linguagem digital.

Nesse novo contexto o emissor não emite mais mensagens, mas constrói um sistema com rotas de navegação e conexões. A mensagem passa a ser um programa interativo que se define pela maneira como é consultado (...) Essas manipulações se processam por meio de uma tela interativa ou interface (...) Por intermédio de instrumentos materiais (tela, mouse, teclado) e imaterias (linguagem de comando), o receptor transforma-se em usuário e organiza sua navegação como quiser em um campo de possibilidades cujas proporções são suficientemente grandes para dar a impressão de infinitude. (SANTAELLA, 2004, p.163)

A interface é, enfim, o lugar onde se desenrola o duelo entre a estratégia do designer e a estratégia do usuário, resume Scolari (2004). Entender a estratégia do usuário seria, então, um grande passo para construir interfaces mais eficientes. Dentro da estratégia do usuário, porém, existem complexidades ainda não esmiuçadas, mas que estão sendo pouco a pouco esclarecidas. Santaella (2004) estudou as habilidades motoras, perceptivas e mentais colocadas em ação pelo usuário, caracterizando-o como um leitor imersivo.

A grande marca identificatório do leitor imersivo é a interatividade. "Outro traço identificador do leitor imersivo encontra-se nas transformações sensórias, perceptivas e cognitivas que emergem nesse tipo de leitura" (SANTAELLA, 2004, p.181). A autora também previu que leitor dos tablets continuaria tendo características cognitivas parecidas com o leitor imersivo dos personal computers:

Não se deve $[. .$.$] concluir que o perfil cognitivo do leitor imersivo [...]$ 
só seja válido para o computador pessoal fixo, conectado por fios, teclado e mouse. $O$ futuro pertencerá aos portáteis. O leitor imersivo continuará existindo, pois navegar significa movimentar-se física e mentalmente em uma miríade de signos, em ambientes informacionais e simulados (SANTAELLA, 2004, p.184)

Santaella (2004) traçou o perfil cognitivo do usuário no ciberespaço. Ela reconheceu três modalidades: o internauta errante, "aquele que pratica a arte da adivinhação"; o internauta detetive, "aquele que segue pistas e aprende com a experiência"; e o internauta previdente, "aquele que sabe antecipar as conseqüências de suas ações". Portanto, para entender a leitura eletrônica, é oportuno considerar estas e outras caracterizações. Chartier (2002), por exemplo, lembra que se trata de outro espaço:

Em primeiro lugar, é preciso considerar que a tela não é uma página, mas sim um espaço de três dimensões, que possui profundidade e que nele os textos brotam sucessivamente do fundo da tela para alcançar a superfície iluminada. Por conseguinte, no espaço digital, é o próprio texto, e não seu suporte, que está dobrado. A leitura do texto eletrônico está concebida nesse caso como desdobramento do texto eletrônico, ou melhor, uma textualidade suave, móvel e infinita. (CHARTIER, 2002, p.31)

Na verdade, há vários modos de ler e há vários tipos de leitores. Ler livros é diferente de ler linguagens hibridas, ou imagens fixas. "A leitura orientada hipermidiaticamente é uma atividade nômade [...] juntando fragmentos que vão se unindo mediante uma lógica associativa e de mapas cognitivos personalizados e intransferíveis" (SANTAELLA, 2004, p.49). Tese esta compartilhada por Chartier (2002): "tal como a navegação pela rede, é uma leitura descontínua, segmentada, fragmentada” (CHARTIER, 2002, p.31).

\section{A LINGUAGEM GESTUAL DOS TABLETS}

As principais diferenças entre os tablets disponíveis no mercado dizem respeito às características de alguns de seus requisitos tecnológicos: tamanho e resolução de tela; processador; capacidade de memória e armazenamento; peso; medidas; e sistema operacional (ver Figura 5). As previsões apontam que, nos próximos anos, outros elementos irão se tornar importantes para medir a capacidade dos tablets. 


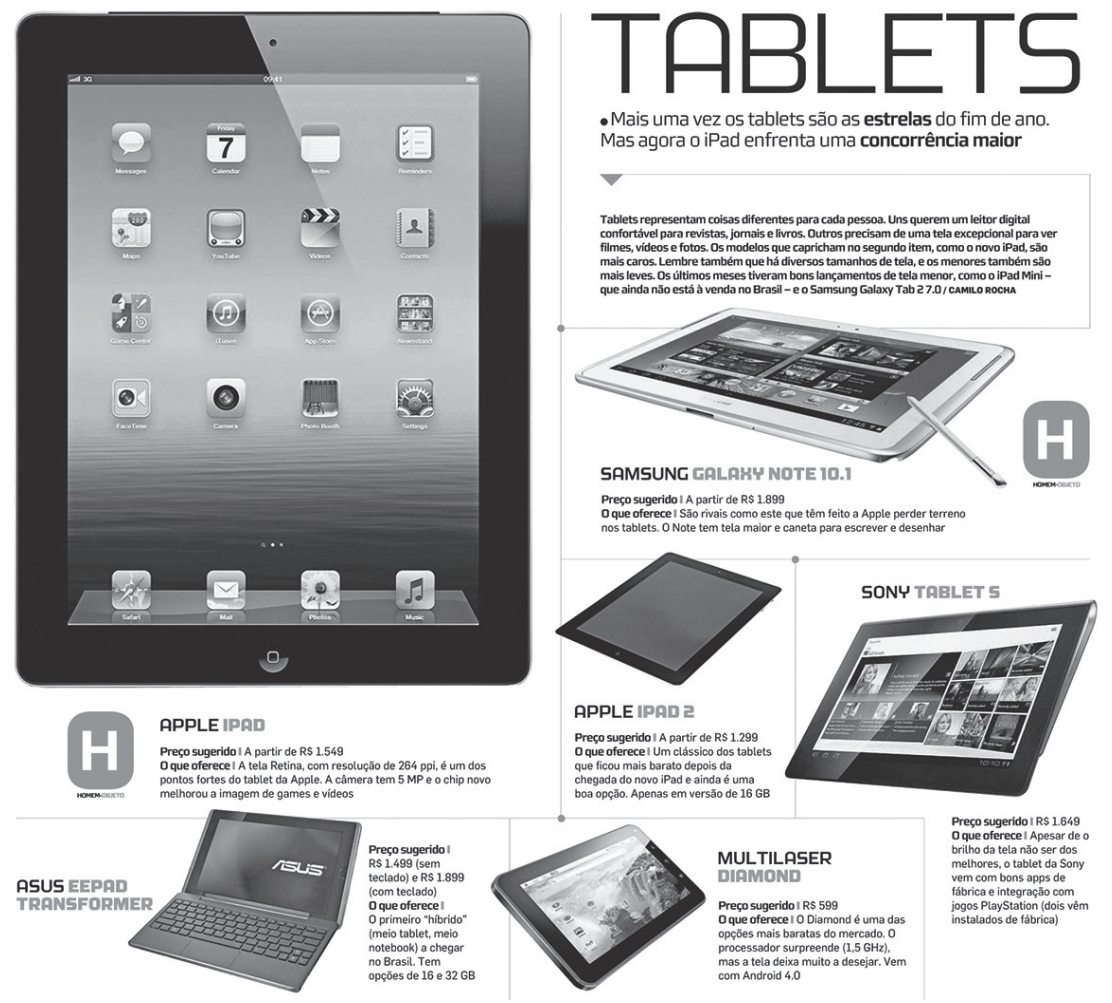

Figura 5- Diferenças entre principais tablets do mercado

Fonte: http://blogs.estadao.com.br/link/files/2012/11/tablets2.jpg

A tecnologia das telas do aparelho, que hoje são predominantemente telas de cristal líquido (LCD), está prestes a se adequar aos Displays Organic Light Emitting Diode (OLED). A capacidade de estimular os sentidos com interfaces mais tácteis ou interfaces de comando de voz também estão no topo das aspirações dos tablets. $O$ rastreamento do olhar - conhecido como Eye Tracking - será desenvolvido para permitir o desencadeamento de ações apenas com a movimentação dos olhos do usuário, além de permitir o mapeamento das áreas mais observadas.

Para além das características envolvendo o hardware dos tablets, também existem questões básicas a serem tratadas no que diz respeito aos softwares do dispositivo. Tablets armazenam programas conhecidos como apps (aplicativos). O conceito de app foi trazido para o mercado pela Apple, com o lançamento do iPhone $3 \mathrm{G}$ e sua loja de aplicativos (Apple Store). Os apps podem ser encontrados em diferentes formatos, tais como: PDF, folio, HTML5, web app e app nativo. Essa variação se dá por conta das tecnologias envolvidas no 
processo de produção e distribuição, tais como linguagens utilizadas e plataformas de armazenamento.

As possibilidades de apresentação de conteúdo didático interativo nos tablets são inimagináveis, de tal forma que o conteúdo possa se apresentar de forma lúdica e de fácil assimilação. A possibilidade do toque e movimentos na tela dos tablets estimula a interação com o conteúdo midiático (texto, fotos, áudio, vídeos, animações, infográficos e mapas) e proporciona ao leitor diversos caminhos na construção de uma narrativa única. Alguns recursos inovadores podem ser verificados no projeto The Next Generation of Digital Books - Our Choice ${ }^{1}$ e a nova versão do livro Alice no País das Maravilhas para iPad², que apresenta uma prévia das novas formas de leitura para tablets. (PAULINO, 2012).

No jornalismo, o aplicativo O Globo A Mais foi desenvolvido para iPad e possui identidade visual atrelada ao jornal O Globo, mas é rico em recursos próprios da plataforma tablet. Vídeos, galerias de fotos, áudio, textos em quadro, imagem em $360^{\circ}$ e visualização de páginas em duas orientações são elementos presentes ao longo da publicação. $O$ texto noticioso em si mantém a essência da estrutura da notícia no impresso (título, lead, sublead, corpo), com a adição de recursos multimidiáticos que já estão alinhados dentro da notícia (o que já representa um passo a frente em relação ao que se costuma ver nas versões digitais dos jornais na web.

O jornal Zero Hora, de maior circulação no Rio Grande do Sul, também possui aplicativo disponível tanto para sistema operacional iOS, da Apple, quanto para sistema Android, da Google. Trata-se de um aplicativo web nativo que acompanha as notícias do site do jornal. Em 2012 o próprio jornal inovou ao lançar um aplicativo extra em formato de web app, batizado de "Olímpico Eterno". O aplicativo agrega conteúdos especiais multimídia sobre o estádio Olímpico. Por ser desenvolvido em web app, ou seja, uma aplicação dentro do navegador, o produto pode ser consumido em qualquer dispositivo com acesso a internet, inclusive computadores desktop.

1 Disponível em < http://pushpoppress.com/ourchoice/>, acesso em: 20/07/2012.

2 Disponível em < http://www.youtube.com/watch?feature=player_embedded\&v=gew68Qj5kxw> acesso em: 20/07/2012. 


\subsection{A linguagem dos gestos nas mãos}

De acordo com Saffer (2009), o gesto é um movimento físico percebido por sensores capazes de respondê-los sem auxílios de periféricos, como teclados ou mouses. A maioria dos gestos interativos pode ser caracterizada em touchscreen e free form. A primeira requer que o usuário toque o dispositivo diretamente para desencadear uma ação; a segunda não requer o toque ou manuseio direto, pois geralmente usa algum tipo de controle ou o movimento do corpo (sem contato).

Os gestos interativos free form já são largamente utilizados nos vídeo games que dispensam o uso dos controles. Nos tablets, as previsões são de que, em breve, o toque na tela não seja a única forma de interação. A tecnologia de controle de gestos permitirá que o usuário acesse o tablet deslizando seus movimentos sem precisar tocar na tela. Esta funcionalidade depende de sensores de câmera com raio infravermelho para detectar os movimentos.

As interfaces gestuais possuem suas potencialidades e limitações: por um lado, interfaces gestuais são mais flexíveis, mais naturais, mais interativas e possuem menos hardware visível. Em contrapartida, interfaces gestuais possuem entrada pesada de dados; dependem muito do aspecto visual; podem ser inapropriadas para o contexto; e demandam fisicamente do usuário.

Saffer (2009) explica que interfaces gestuais são constituídas por três elementos: sensores (que detectam a interação), comparadores (que interpretam o evento) e os atuadores (que executam procedimentos em resposta ao evento interpretado). Há um grande conjunto de tipos de sensores atualmente: pressure (detectam quaisquer eventos relacionados ao toque); light (detectam luminosidade de um ambiente); proximity (detectam proximidade de objetos); acoustic (detectam sonoridade); tilt (detectam inclinação); motion (detectam movimento e velocidade); e orientation (detectam posição e direção).

Os melhores gestos interativos são aqueles que combinam sensores corretos com um movimento humano profundamente envolvido em uma ação. A partir daí, o autor recorre aos estudos antropométricos do desenhista industrial Henry Dreyfuss (1955), que se dedicou a pesquisar as medidas humanas e os confortos produzidos por elas. Esses estudos ajudaram Dreyfuss (figura 6) a criar vários objetos funcionais, como telefones. 


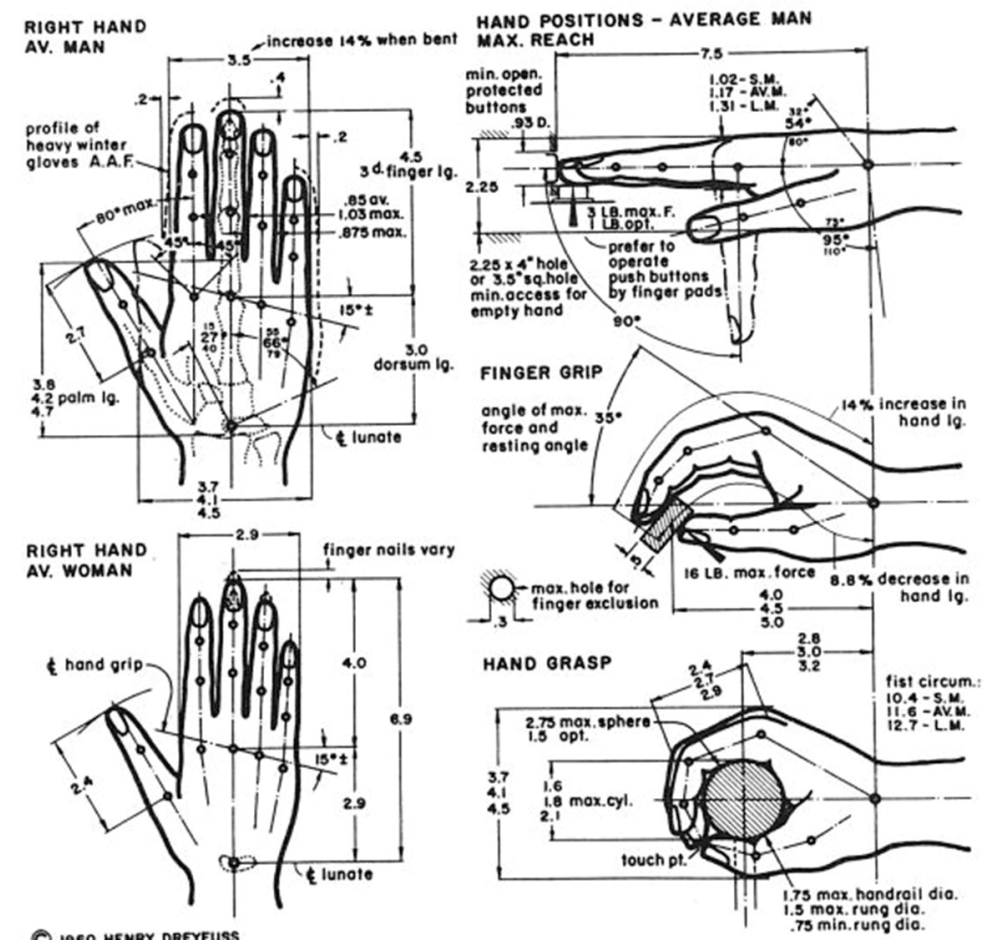

Figura 6- Medidas das mãos de homens, mulheres e crianças

Fonte: DREYFUSS, Henry. Designing for people. New York: Simon and Schuster, 1955.

Os gestos possuem atribuições fundamentais a serem analisadas: porte, posição, movimento, duração, sequência, número de participantes, pressão, tamanho, orientação e número de objetos (combinações) envolvidos. O corpo é o dispositivo de entrada principal para uma interface gestual, de modo que os designers e desenvolvedores deveriam conhecer o sistema básico do corpo, da mesma forma que conhecem o sistema básico computacional.

Há muitos anos a interatividade gestual tem sido usada nos dispositivos, mas ainda perduram os padrões de interface baseados na metáfora do desktop desenvolvido nos anos 60, isto é: cursores, mouses, duplo-clique, clique direito, botões padrão, desfazer etc. Acredita-se, porém, que os métodos de manipulação indireta vão ser progressivamente substituídos pelos métodos de manipulação direta. Agner (2001) admite que há convenções de interfaces empregadas nas interações WIMP que funcionam adequadamente para gestos, como os atos de "selecionar", "arrastar-e-soltar" ou "rolagem (scrolling)". Em contrapartida, há notáveis exceções, como: cursores; mouseover; duploclique; e clique com botão direito.

Saffer (2009), então, destaca alguns padrões que seriam específicos de te- 
las sensíveis ao toque. Na Figura 7 eles estão ilustrados. São eles: tocar para abrir/ativar; tocar para selecionar; tocar para parar; arrastar para mover o objeto; deslizar para rolar; dois dedos para rolar; girar para rolar; agitar; beliscar para encolher; espalhar para ampliar; dedos fantasmas (ghost fingers); mover o corpo para ativar; apontar para selecionar/ativar.
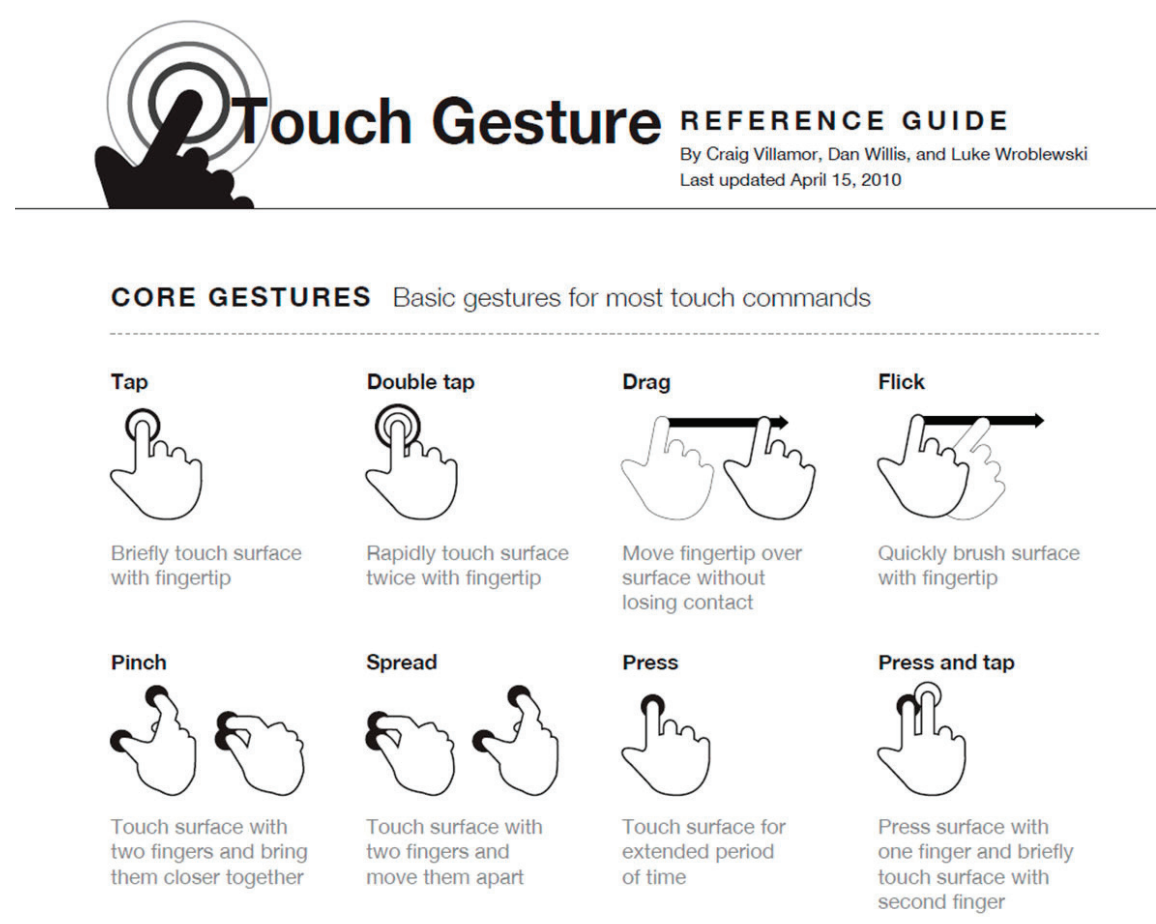

Figura 7- Gestos básicos para os comandos de toque

Fonte: VILLAMOR, C.; WILLIS, Dan; WROBLEVSKI, Luke. Touch Gesture Reference Guide. 2010

Além desses gestos padronizados, existem possibilidades de interatividade típicas para interfaces em tablets. Estes recursos interativos são baseados em possibilidades de intervenção do leitor sobre o conteúdo. Esta interatividade permite ao leitor criar seu próprio caminho de navegação e descobrir novas informações por meio do desencadeamento de uma ação. Abaixo, são alguns dos recursos interativos para tablets: 
Tabela 1 - Recursos interativos nos tablets

\begin{tabular}{|l|l|}
\hline RECURSO & FINALIDADE \\
\hline $\begin{array}{l}\text { Sequência de imagens } \\
\text { (image sequence) }\end{array}$ & sequência de imagens que dão o efeito de movimento \\
\hline $\begin{array}{l}\text { Panorama / Panorama e } \\
\text { Zoom }\end{array}$ & $\begin{array}{l}\text { navegação dentro de uma imagem, visualizando diferentes } \\
\text { planos }\end{array}$ \\
\hline Conteúdo da web & integração de sites e conteúdo HTML \\
\hline Quadro com rolagem & $\begin{array}{l}\text { permissão de conteúdos extensos (textos, imagens) dentro } \\
\text { de um mesmo quadro, expandido por meio da rolagem } \\
\text { abertura de uma imagem ou massa de texto por meio de uma } \\
\text { ação de um botão dentro de outra imagem }\end{array}$ \\
\hline Hotspot & arrastar e soltar elementos que se encaixam ou não \\
\hline $\begin{array}{l}\text { Drag and Drop/Drag and } \\
\text { Switch }\end{array}$ & listagem de imagens que se alternam em planos \\
\hline Galeria & $\begin{array}{l}\text { objetos que se movimento por meio de uma simulação de for- } \\
\text { ça vinda da ação do usuário } \\
\text { edição em imagens sobrepostas }\end{array}$ \\
\hline Gravidade &
\end{tabular}

\subsection{A usabilidade nos tablets}

Finalmente, após suas análises primeiras, Saffer (2009) lança aquelas que seriam as boas práticas na construção de uma interface gestual:

* Detectabilidade: refere-se à importância de que determinado objeto permita a ação;

* Confiabilidade: a segurança da interface;

* Responsividade: repostas rápidas;

* Adequação: adaptação ao contexto;

* Significância: responder às necessidades do usuário;

* Inteligência: estar a serviço do usuário;

* Sutileza: prever as necessidades do usuário;

* Divertimento: ser lúdica e gerar envolvimento;

* Estética: agradável aos sentidos; e

* Ética: não gerar nenhum tipo de constrangimento.

Esta categorização proposta por Saffer (2009) oportunamente pode ser comparada com outra reconhecida no mundo digital: as premissas de usabilidade na web propostas por Jakob Nielsen (2000) para auxiliar no desenvolvimento de sites: 


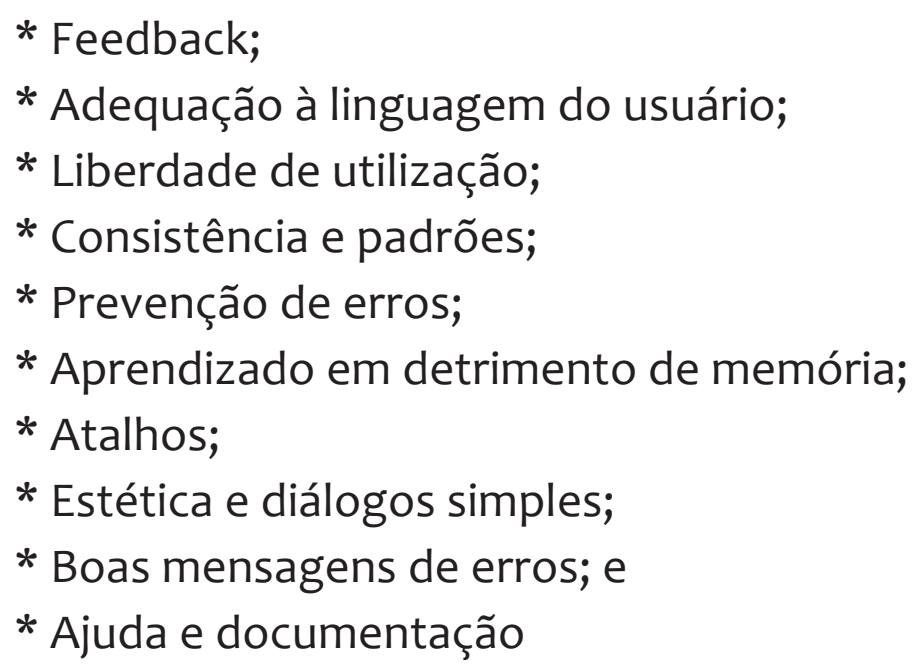

A primeira orientação de Saffer (2009) diz respeito à detectabilidade. Neste quesito, o autor está se referindo às affordances, ou seja, o aspecto de design do objeto que sugere como ele deve ser usado; é a imagem visual para o uso funcional. Este quesito parece especialmente interessante para as interfaces gestuais dos tablets, uma vez que a analogia com a manipulação de objetos concretos pode ser usada de forma criativa. Nos pontos relacionados à "adaptação ao contexto" e à "ética", o autor lembra que o gesto não se limita à relação única com o dispositivo. Os gestos possuem significados diferentes em contextos diferentes. Assim, a interface nunca deve levar o usuário a acionar um gesto que possa constrangê-lo.

Em 2010, Nielsen publicou um relatório sobre testes de usabilidade com as interfaces então disponíveis no iPad, o tablet mais conhecido do mundo. O pesquisador identificou diversos problemas e apontou soluções. Em 2011, um novo relatório trouxe outras conclusões e apontou erros persistentes. Neste novo teste foram chamados 16 usuários com pelo menos dois meses de experiência com o tablet. Eles testaram 26 aplicativos e 6 sites. A pesquisa concluiu que:

1) Áreas para toque não são intuitivas ou instrutivas

2) A ausência do botão "voltar" deixa os usuários desorientados

3) O aumento do número de aplicativos deixou os usuários mais acostumados à ferramenta;

4) As interfaces não apresentam muitos formulários para evitar a digitação nos teclados virtuais;

5) Splash-screens (imagens que aparecem na espera de uma atualização) irritam os usuários; 
6) O efeito "deslizar" confunde o usuário quando é usado na mesma publicação para funcionalidades diferentes;

7) Excesso de possibilidades de navegação em aplicativos cansam o usuário;

8) Os tablets são compartilhados, logo, os aplicativos deveriam ser chaveados de acordo com o usuário;

9) Os aplicativos são a melhor solução quando o foco é interação com o usuário. Caso contrário, o site é a melhor opção; e

10) Os iPads são usados para jogos, email, redes sociais, vídeos e notícias. Buscas e compras são preferíveis nos personal computers.

A pesquisa de Nielsen reforça algumas regras básicas do design: a resolução das imagens deve facilitar o toque e não confundir o usuário; os espaçamentos dos elementos do layout não devem induzir toques equivocados em áreas sensíveis; não é aconselhável o uso e imagens de alta resolução em elementos interativos; e o corpo das fontes utilizadas deve estar adequado.

\section{CONSIDERAÇÕES FINAIS}

Ainda não é possível reconhecer padrões de interatividade consagrados pelo uso e pelo tempo em interfaces gestuais nos tablets. Em contrapartida, os padrões de usabilidade nativos da web em computadores fixos e nos jogos eletrônicos estão mais bem estabelecidos e podem auxiliar na compreensão desta relação do usuário com a interface digital móvel. Conceitos como "respostas claras e imediatas"; "segurança e confiabilidade"; "linguagem amigável e contextualizada"; "simplicidade"; e "clareza" de navegação são facilmente transpostos para as plataformas móveis. Contudo, esta transposição deve vir adaptada às características dos tablets.

O estabelecimento de padrões de navegação nos tablets é o desafio em meio a uma infinidade de aplicativos desenvolvidos por experimentação. Dessa forma, cada desenvolvedor tende a oferecer possibilidades novas navegação, confundindo o usuário. Hoje em dia, portanto, é muito comum que as publicações para tablets venham acompanhadas por guias de navegação. Esta realidade parece estranha quando se fala em sites. Dessa maneira, o atual desafio é investir em pesquisas de usabilidade e interação centradas no usuário para que sejam desenvolvidas e registradas as boas práticas de desenho de interfaces nos tablets. 


\section{REFERÊNCIAS}

AGNER, Luiz. Em busca de um olhar interdisciplinar sobre a arquitetura de informação, a usabilidade e a metacomunicação em dispositivos móveis com interfaces gestuais. Anais do Simpósio Nacional da ABCiber. Florianópolis: ABCiber, 2011. Disponível em:<http://www. agner.com.br/wp-content/uploads/2012/06/ARTIGO-LUIZ-AGNER-USIHC-2012.pdf>. Acesso em: 20 dez 2012

BUDIU, R; NIELSEN, Jakob. iPad App and Website Usability. Nielsen Norman Group. 2n Edition. 2011

CHARTIER, Roger. Os desafios da escrita. São Paulo. Ed. Unesp, 2002

HAYWARD, Vincent, ASTLEY, Oliver R., CRUZ-HERNANDEZ, Manuel, GRANT, Danny and ROBES-DE-LA-TORRE, Gabriel. Haptic interfaces and devices. In: Sensor Review Volume 24 • Number $1 \cdot 2004 \cdot$ pp. 16-29.

MCLUHAN, Marshall. Os meios de comunicação como extensões do homem. São Paulo. Cultrix, 1977

NIELSEN, Jakob. Usability Engineering, Editora Academic Press, Boston, 1993.

NIELSEN, Jakob. Projetando Websites. Editora Campus, Rio de Janeiro, 2000.

PAULINO, R. C. R. . Revistas Digitais: uma abordagem sóciotecnológica de um sistema hipermídia para tablets. In: X Encontro Nacional dos Pesquisadores em Jornalismo, 2012, Curitiba. X Encontro Nacional dos Pesquisadores em Jornalismo. Brasília: Associação Brasileira de Pesquisadores em Jornalismo, 2012.

PRIMO, Alex . Interação mediada por computador: comunicação, cibercultura, cognição. Porto Alegre: Sulina, 2007. 240p

SAFFER, Dan. Designing gestural interfaces.O'Reilly, Sebastopol, 2009.

SANTAELLA, Lúcia. As linguagens como antídotos ao midiacentrismo. Revista Matrizes. $n^{\circ}$ 1. Outubro. 2007

SANTAELLA, Lúcia. Navegar no Ciberespaço. O perfil cognitivo do leitor imersivo. São Paulo: Paulus, 2004

SARAIVA, A. J.; ALMEIDA, A; FARIA, M.; MOREIRA, L. B. Sistema integrado para incisão cirúrgica com bisturi virtual utilizando o dispositivo háptico Phantom Omni. Monografia apresentada ao Curso de Graduação em Ciência da Computação do Centro Universitário da Faculdade de Engenharia Industrial. São Bernardo do Campo. 2010.

SCOLARI, Carlos. Hacer Clic. Hacia una sociosemiótica de lasinteracionesdigitales. Barcelona: Gedisa. 2004

SILVA, E. L.; MENEZES, E. M. Metodologia da pesquisa e elaboração de dissertação. 3 ed. Rev. Atual. Florianópolis: Laboratório de Ensino à Distância da UFSC, 2001.

WOLF, M. Proust and the squid: The story and science of the reading brain. NY: HarperCollins, 2007 
RECEBIDO EM: 17/05/2013

ACEITO PARA PUBLICAÇÃO: 16/12/2013

\section{Vivian Rodrigues de Oliveira}

Mestre em Jornalismo pela Universidade Federal de Santa Catarina (UFSC) em Florianópolis (SC), Brasil. Especialista em Gestão da Comunicação Pública e Empresarial pela Universidade Tuiuti do Paraná (UTP). Bacharel em Comunicação Social (Jornalismo) pela Universidade de Brasília (2011).

\section{Rita de Cássia Romeiro Paulino}

Doutora em Engenharia e Gestão do Conhecimento pela Universidade Federal de Santa Catarina (UFSC) em Florianópolis (SC), Brasil. Docente do curso de Pós-Graduação em Jornalismo (POSJOR) e do curso de Jornalismo da UFSC. 
